\title{
Spatio-temporal Patterns of Net Primary Production(NPP) in Weihe Watershed(China) and its Response to Environmental Factors
}

\author{
Lixia Wang ${ }^{1}$ \\ ${ }^{1}$ Affiliation not available
}

October 21, 2020

\begin{abstract}
Carnegie-Ames-Stanford Approach and CA-Markov models are coupled to simulate and predict NPP in the Weihe Watershed to explore the spatial and temporal distribution of NPP and its dynamic changes. Correlation analysis was used to quantitatively evaluate the NPP response to environmental factors.Results showed that: (1) Seasonal and periodic changes were evident within a year. The interannual change showed a rising trend. According to forecast results, the NPP status of vegetation in the Weihe Watershed will improve and continue to grow over the next decade. (2) Spatially, the NPP distribution is significantly different, showing an overall high distribution in the south and east and low distribution in the north and west. (3) The response of vegetation NPP in the Weihe Watershed to environmental factors is significant but varied. The NPP response to temperature and precipitation was mildly positively correlated. The NPP showed trends of stabilizing, then sharply decreasing, and finally increasing with the increase in altitude, as well as continuously increasing with the increase in slope. Meanwhile, the vegetation NPP values of the northern and western slopes were higher than those of the southern and eastern slopes. (4) The CASA and CA-Markov models have high coupling degrees.
\end{abstract}

\section{Hosted file}

manuscript.pdf available at https://authorea.com/users/369048/articles/487983-spatiotemporal-patterns-of-net-primary-production-npp-in-weihe-watershed-china-and-itsresponse-to-environmental-factors 